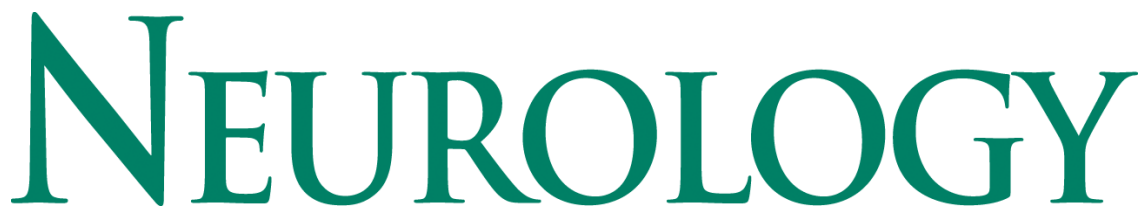

\title{
Longitudinal study of effects of patient characteristics on direct costs in Alzheimer disease
}

C. W. Zhu, N. Scarmeas, R. Torgan, et al.

Neurology 2006;67;998; Prepublished online August 16, 2006;

DOI 10.1212/01.wnl.0000230160.13272.1b

This information is current as of December 3, 2010

The online version of this article, along with updated information and services, is located on the World Wide Web at:

http://www.neurology.org/content/67/6/998.full.html

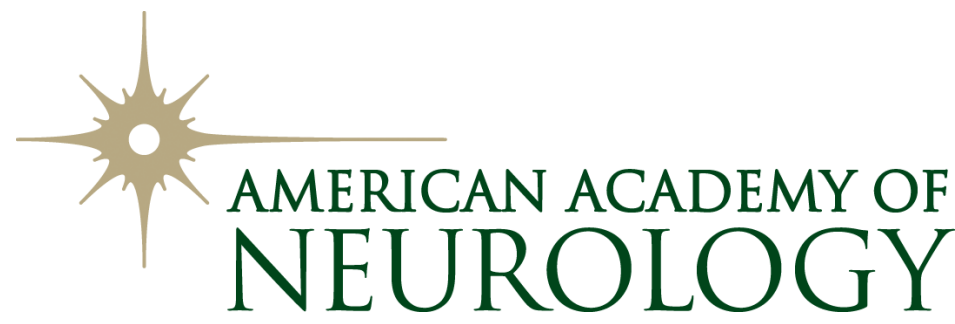




\title{
Longitudinal study of effects of patient characteristics on direct costs in Alzheimer disease
}

\author{
C.W. Zhu, PhD; N. Scarmeas, MD, MSc; R. Torgan, MPH; M. Albert, PhD; J. Brandt, PhD; \\ D. Blacker, MD, ScD; M. Sano, PhD; and Y. Stern, PhD
}

\begin{abstract}
Objectives: To estimate long-term trajectories of direct cost of caring for patients with Alzheimer disease (AD) and examine the effects of patients' characteristics on cost longitudinally. Methods: The sample is drawn from the Predictors Study, a large, multicenter cohort of patients with probable AD, prospectively followed up annually for up to 7 years in three university-based AD centers in the United States. Random effects models estimated the effects of patients' clinical and sociodemographic characteristics on direct cost of care. Direct cost included cost associated with medical and nonmedical care. Clinical characteristics included cognitive status (measured by Mini-Mental State Examination), functional capacity (measured by Blessed Dementia Rating Scale [BDRS]), psychotic symptoms, behavioral problems, depressive symptoms, extrapyramidal signs, and comorbidities. The model also controlled for patients' sex, age, and living arrangements. Results: Total direct cost increased from approximately $\$ 9,239$ per patient per year at baseline, when all patients were at the early stages of the disease, to $\$ 19,925$ by year 4 . After controlling for other variables, a one-point increase in the BDRS score increased total direct cost by 7.7\%. One more comorbid condition increased total direct cost by 14.3\%. Total direct cost was $20.8 \%$ lower for patients living at home compared with those living in an institutional setting. Conclusions: Total direct cost of caring for patients with Alzheimer disease increased substantially over time. Much of the cost increases were explained by patients' clinical and demographic variables. Comorbidities and functional capacity were associated with higher direct cost over time.
\end{abstract}

NEUROLOGY 2006;67:998-1005

Alzheimer disease $(\mathrm{AD})$ is the third most costly disease to society in the United States. ${ }^{1}$ Average annual costs of caring for patients with $\mathrm{AD}$ have been estimated at $\$ 80$ billion to $\$ 100$ billion in the United States. ${ }^{2}$ Several important factors that influence the cost of $\mathrm{AD}$ have been identified in the literature, including dementia disease severity, ${ }^{3-12}$ comorbid medical conditions,,${ }^{7,13,14}$ behavioral problems, ${ }^{12,15,16}$ neuropsychiatric symptoms, ${ }^{17}$ or extrapyramidal signs. ${ }^{18}$ However, much of the $\mathrm{AD}$ cost literature remains cross-sectional and cannot examine cost trajectories over time. The two studies that followed patients over time either used data from two time points over short periods of time or used a small nonrepresentative sample; they are therefore limited their ability to estimate long-term disease cost trajectories. ${ }^{19,20}$ Consequently, we do not yet know how cost changes as disease progresses nor the relationship between cost and clinical factors over time.

Direct costs of $\mathrm{AD}$ related to medical and nonmedical care are substantial. In an earlier work from the Predictors Study, a large, multicenter study of patients with probable $\mathrm{AD}$ followed from early stages of the disease, we examined cross-sectionally the association between patient characteristics and direct costs. $^{21}$ In this study, we aim to extend our previous work and estimate empirically long-term trajectories of direct cost of $\mathrm{AD}$ and relate them to patients' clinical and sociodemographic characteristics.

Methods. Sample. The sample used in this study is drawn from the Predictors 2 cohort and consisted of 204 patients with probable $\mathrm{AD}$ recruited from three sites: Columbia University Medical Center, Johns Hopkins School of Medicine, and Massachusetts General Hospital. The study was approved by each local

This article was previously published in electronic format as an Expedited E-Pub on August 16, 2006, at www.neurology.org.

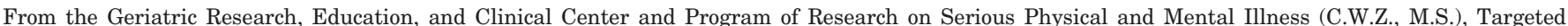

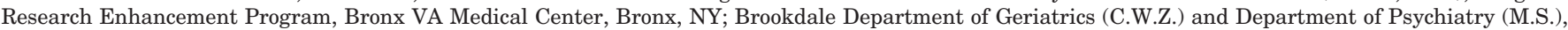

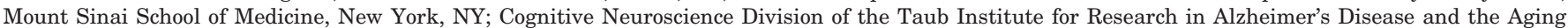

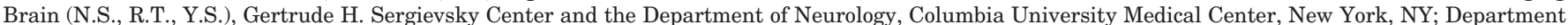

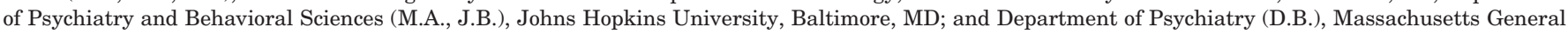
Hospital, Harvard Medical School, Boston, MA.

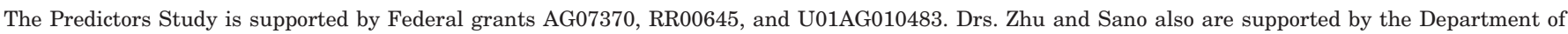

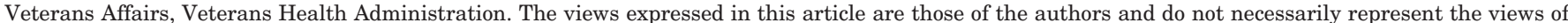
the Department of Veterans Affairs.

Disclosure: The authors report no conflicts of interest.

Received January 27, 2006. Accepted in final form April 11, 2006.

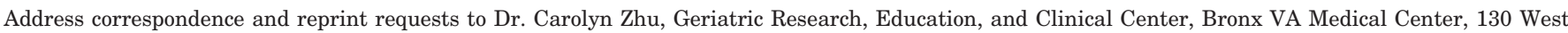
Kingsbridge Road, Bronx, NY, 10468; e-mail: carolyn.zhu@mssm.edu 
institutional review board. The inclusion and exclusion criteria are fully described elsewhere. ${ }^{22-24}$ Briefly, subjects met DSM-III-R criteria for primary degenerative dementia of the Alzheimer type and National Institute of Neurological Disorders and StrokeAlzheimer's Disease and Related Disorder Association criteria for probable AD. Enrollment required a modified Mini-Mental State Examination score of 30 or greater, equivalent to a score of approximately 16 or greater on the Folstein Mini-Mental State Examination (MMSE). ${ }^{25,26}$ Because subjects were followed up at academic $\mathrm{AD}$ centers, they were well characterized with high degrees of certainty in their $\mathrm{AD}$ diagnosis.

Recruitment of patients in the Predictors Study began in 1998. For the current analysis sample, baseline data were collected for $13.3 \%$ of patients in $1998,8.3 \%$ in $1999,24.3 \%$ in $2000,26.0 \%$ in $2001,15.5 \%$ in $2002,11.1 \%$ in 2003 , and $1.1 \%$ in 2004 . After the baseline interview, all patients were followed semiannually, with annual assessments of resource utilization. At this point in the study, patients have each had at least one assessment in resource utilization, and $82.4 \%$ have had two or more assessments. Specifically, 36 patients had one assessment only (at baseline), 62 had two assessments (baseline and one follow-up visit), 51 had three assessments (baseline and two follow-up visits), 36 had four assessments, 11 had five assessments, and 2 had six assessments. Median follow-up for the cohort was 2 years, and maximum follow-up time was 7 years. Patients who did not respond at a particular visit could respond at a subsequent visit. We excluded 6 patients with missing cost data from our analysis sample. Each of these 6 patients was assessed once at baseline and would have contributed 6 observations to the analysis sample. The final analysis sample consisted of 524 observations from 198 patients.

Measures. Data on several clinical characteristics that can be assessed easily and reliably by a clinician were recorded at each visit. At baseline and annually thereafter, data on patients' utilization of seven domains of medical and nonmedical care also were collected. We converted physical quantities for each domain of care into monetary values based on cost estimates from several public sources. ${ }^{27-30}$ We summed costs across all domains to obtain a total direct cost as a measure of intensity of resource utilization. We briefly describe below the clinical characteristics, health services utilization, and cost outcomes used in this study. Details of our costing methods were reported in an earlier study. ${ }^{21}$

Clinical characteristics. Disease progression was characterized by transition from milder stages of dementia to more severe stages, measured by MMSE. ${ }^{25}$ Higher MMSE scores indicate better cognitive status. Blessed Dementia Rating Scale (BDRS) Parts I (Instrumental Activities of Daily living, IADLs) and II (Basic Activities of Daily living, BADLs) was used to assess patients' functional capacity. ${ }^{31}$ This is a 17-point scale, with higher scores indicating worse functional status. Columbia University Scale for Psychopathology in Alzheimer's Disease, a semistructured interview administered by a physician or a trained research technician, was used to measure the presence or absence of psychotic symptoms, behavior problems, and depressive symptoms. ${ }^{32}$ Following previous work, ${ }^{33,34}$ we constructed a dichotomous variable to indicate the presence of psychotic symptoms if the patient had any delusions, hallucinations, or illusions. We constructed a dichotomous variable to indicate the presence of behavioral problems if the patient had any of the following five symptoms: wandering away from home or caregiver, verbal outbursts, physical threats or violence, agitation or restlessness, or sundowning (more confusion at night or during the evening, compared with during the day). We also constructed a dichotomous variable to indicate the presence of depressive symptoms if the patient had any depressed mood (i.e., sad, depressed, blue, down in the dumps) and either had difficulty sleeping or had a change in appetite. A modified Unified Parkinson's Disease Rating Scale was used to measure the presence or absence of extrapyramidal signs (EPS) ${ }^{35,36}$ Following our previous work, 24,37 we constructed a dichotomous indicator for the presence of EPS if any of the following 11 items was rated 2 or higher (with 0 being normal and 4 indicating maximum impairment): speech, facial expression, tremor at rest, neck rigidity, right arm rigidity, left arm rigidity, right leg rigidity, left leg rigidity, posture, gait, or bradykinesia. Patients' medical histories were used to construct a modified version of the Charlson index of comorbidity. ${ }^{34,37,38}$ Comorbidities included items for myocardial infarction, congestive heart failure, peripheral vascular disease, hypertension, chronic obstructive pulmonary disease, arthritis, gastrointestinal diseases, liver disease, diabetes, chronic renal disease, and systemic malignancy from the baseline visit. No patients with strokes, metastatic tumors, or AIDS were included in the sample. Finally, disease duration was estimated by a neurologist based on interviews with the patient and informant at the baseline visit.

Sociodemographic characteristics. At the baseline visit, demographic characteristics (e.g., age, ethnicity, sex, education) were recorded. Because patients' living arrangement may change over time and patterns of health service utilization and costs may differ substantially between patients in different living arrangements, ${ }^{39}$ information on patients' living arrangements was collected at each follow-up visit.

Outcomes. Patients and informants reported utilization of seven domains of medical and nonmedical care. Medical care included hospitalization, outpatient treatment and procedures, assistive devices, and medications. Nonmedical care included home health aides, respite care, and adult day care. We annualized utilization rates when domains were reported for 3 months (outpatient medical test, treatments, and procedures; nonmedical care) and 6 months (medications). To convert physical quantities of resource use into monetary values, we multiplied for each domain the quantity used for that domain and the corresponding unit cost, and then summed across all domains to obtain a total direct cost as a measure of intensity of total resource utilization. Unit costs for each domain were obtained from several databases and described in detail in an earlier report. ${ }^{21,27-30}$ All cost values were adjusted to constant 2004 dollars using the medical care component of the Consumer Price Index. ${ }^{40}$

Analysis. Because total direct cost was highly skewed to the right (skewness $=2.26$ ), we examined log cost as the dependent variable. Three patients at five different visits reported zero cost, generating missing values on log costs. Instead of arbitrarily adding a constant (e.g., \$1) to the cost measure before logtransformation, we excluded these five observations. Because the number of observations with zero cost was so small, excluding them did not change the cost distribution in the sample. The Shapiro-Wilk W test did not reject the hypothesis that log cost was normally distributed $(p>0.08)$.

In our multivariate analysis, we aimed to estimate two components of change in total direct cost trajectories as disease progresses over time: within-person change and between-person change. We used random effects models (also known as hierarchical linear models, multilevel models, or random coefficient models) to estimate these changes over time. ${ }^{41,42}$ The unit of observation was person-year.

We hypothesized an overall upward trajectory of direct costs for the sample as a whole. Time in this study was measured in years after baseline (Time 0 ). We began by estimating a simple model that included an intercept and time (year) as fixed effects, and a random intercept term. In this model, the (fixed) intercept estimates the average baseline cost. The coefficient on time (year) estimates the average linear trend in direct costs over time. The random intercept estimates deviations from average cost trajectories for each patient. We then included a term for time (year) squared in the estimation model. The coefficient on the timesquared term was statistically insignificant and was dropped in subsequent models. In the next step, we included a random slope in our estimation model to allow subjects to differ in their overall rate of cost increase. Likelihood ratio tests suggested that cost trajectories differed significantly across patients. Finally, we included clinical and sociodemographic variables as fixed effects to control for any systematic differences in our sample on these variables. The clinical variables included MMSE score, BDRS score, number of comorbidities, and presence or absence of behavioral problems, EPS, depressive and psychotic symptoms. Each of the clinical variables was measured at each visit and was therefore time variant.

Sociodemographic variables included age at baseline, sex, and living arrangement at each visit. Patients' living arrangement at each visit was measured in the following four categories: at home, in retirement homes, in assisted living facilities, or in nursing homes. These four categories initially were entered separately in the estimation model to examine the effects of different care environments on costs. However, earlier estimation results suggested that costs were not significantly different between patients who lived in retirement homes, in assisted living facilities, or in nurs- 
ing homes, possibly because of the relatively small proportions of patients in these groups in our sample. Therefore, these three categories were combined in the final estimation model. Because the patients in the sample were overwhelmingly white (96\%), we did not include race as an explanatory variable. In addition, we controlled for site differences by including site dummy variables. In this model, the fixed effects parameters are interpreted as the average effect of each explanatory variable. The random effects are interpreted as deviations from the average for each patient.

Our final model took the form

$$
\mathrm{y}_{\mathrm{it}}=\beta_{1}+\beta_{2} \text { year }_{\mathrm{it}}+\beta_{3} \mathrm{w}_{\mathrm{it}}+\zeta_{1 \mathrm{t}}+\zeta_{2 \mathrm{t}} \text { year }_{\mathrm{it}}+\varepsilon_{\mathrm{it}},
$$

where $y_{i t}$ is the log cost of patient $i$ at year $t$, year $r_{i t}$ is the corresponding year, $w_{i t}$ refers to the clinical and sociodemographic variables, $\zeta_{1 \mathrm{t}}$ is the random intercept that allows baseline cost of each patient to differ from average cost, $\zeta_{2 t}$ is the random slope that allows the rate of change for each patient to differ from average rate of change over time, $\varepsilon_{i t}$ is the random error, and the $\beta s$ are the estimated fixed effects parameters.

Because our dependent variable was log-transformed, the coefficient estimates are semielasticities. The interpretation of the coefficient estimates requires some care. For continuous explanatory variables, a coefficient of $\hat{\beta}$ estimates the proportional change in direct cost for a unit change in the explanatory variable, holding all other variables constant. That is, for a unit increase in the explanatory variable, direct cost increases by $100 \hat{\beta}$ percent. For dichotomous explanatory variables, the corresponding proportional change on cost of the explanatory variable from the reference group is estimated by

$$
\left(e^{\frac{\hat{\beta}-\mathrm{V}(\hat{\beta})}{2}}-1\right),
$$

holding all other variables constant..$^{43}$ We interpreted these proportional changes as the marginal effect of each explanatory variable on direct cost. We used a Wald test to test the hypothesis that all variables in the model were jointly significant. All analyses were performed using Stata 9.0.44

Results. Sociodemographic and clinical characteristics. Longitudinal patterns of demographic and clinical characteristics of the sample are shown in table 1 . The first row in table 1 presents the number of patients who contributed to our analysis sample at each visit. Differences in the number of observations over the years of follow-up reflect the continuous accrual of subjects even at present and patient deaths (8\%). During the period in which each subject was followed up, missed visits were rare: $15.6 \%$ missing one visit, $2.5 \%$ missed two visits, and $1 \%$ missed three visits. Because only eight patients remained in years 5 and 6 (contributing to 12 observations), descriptive statistics of the sample were presented for the first 4 years of the study. The average patient in the sample was 76.3 years old. Slightly more than half were women $(55.9 \%)$. The patients in the sample were largely non-Hispanic white (95.8\%), well educated (with an average of 14.3 years of schooling), and either married (59.9\%) or widowed $(31.1 \%)$. At baseline, $85.9 \%$ of the patients lived at home, $8.1 \%$ lived in a nursing home, and $6 \%$ lived in a retirement home or an assisted living facility. There were no differences in subjects' sociodemographic characteristics across sites.

Because of the study inclusion criteria, all patients were initially at the early stages of $\mathrm{AD}$. At baseline, most patients $(95 \%)$ were mildly demented, with a Clinical Dementia Rating of 1,45 the mean MMSE score was 22.0 (SD = 3.7 ), and the mean BDRS score was 3.6 ( $\mathrm{SD}=2.2$ ). As expected, patients' cognition and function worsened over time. Over time, MMSE and BDRS scores both worsened monotonically. By the end of the study period or the last assessment for patients who died, $71.2 \%$ of the cohort remained mildly demented, $19.2 \%$ were moderately de-
Table 1 Descriptive statistics of the sample demographic and

\begin{tabular}{|c|c|c|c|c|c|c|}
\hline & Baseline & $\begin{array}{c}\text { Year } \\
1\end{array}$ & $\begin{array}{c}\text { Year } \\
2\end{array}$ & $\begin{array}{c}\text { Year } \\
3\end{array}$ & $\begin{array}{c}\text { Year } \\
4\end{array}$ & $\begin{array}{c}\text { All } \\
\text { sample }\end{array}$ \\
\hline Sample size* & 198 & 132 & 93 & 59 & 30 & 524 \\
\hline \multicolumn{7}{|l|}{ Sociodemographic variables } \\
\hline $\begin{array}{l}\text { Age at baseline, } \\
\text { mean (SD), y }\end{array}$ & $\begin{array}{l}76.4 \\
(8.1)\end{array}$ & $\begin{array}{l}76.7 \\
(8.2)\end{array}$ & $\begin{array}{l}76.8 \\
(8.5)\end{array}$ & $\begin{array}{c}75.5 \\
(7.4)\end{array}$ & $\begin{array}{l}74.6 \\
(8.2)\end{array}$ & $\begin{array}{l}76.3 \\
(8.1)\end{array}$ \\
\hline Female, $\%$ & 59.1 & 55.3 & 58.1 & 47.5 & 50.0 & 55.9 \\
\hline \multicolumn{7}{|l|}{ Race, $\%$} \\
\hline White & 94.9 & 97.0 & 94.6 & 96.6 & 96.7 & 95.8 \\
\hline Black & 4.5 & 2.3 & 4.3 & 3.4 & 3.3 & 3.6 \\
\hline Other & 0.5 & 0.8 & 1.1 & 0.0 & 0.0 & 0.6 \\
\hline $\begin{array}{l}\text { Years of schooling, } \\
\text { mean (SD) }\end{array}$ & $\begin{array}{c}14.3 \\
(3.2)\end{array}$ & $\begin{array}{l}14.6 \\
(3.1)\end{array}$ & $\begin{array}{l}14.3 \\
(3.2)\end{array}$ & $\begin{array}{c}14.5 \\
(3.2)\end{array}$ & $\begin{array}{l}13.6 \\
(3.7)\end{array}$ & $\begin{array}{c}14.3 \\
(3.2)\end{array}$ \\
\hline \multicolumn{7}{|l|}{ Marital status, $\%$} \\
\hline Married & 60.1 & 59.8 & 57.0 & 61.0 & 66.7 & 59.9 \\
\hline Widowed & 30.8 & 31.1 & 31.2 & 33.9 & 26.7 & 31.1 \\
\hline Other & 9.1 & 8.3 & 8.6 & 1.7 & 6.7 & 7.8 \\
\hline \multicolumn{7}{|l|}{ Living arrangement, $\%$} \\
\hline At home & 85.9 & 77.3 & 75.3 & 69.5 & 83.3 & 79.6 \\
\hline Nursing home & 8.1 & 11.4 & 12.9 & 16.9 & 3.3 & 10.5 \\
\hline Retirement home & 2.5 & 4.5 & 1.1 & 1.7 & 0.0 & 2.5 \\
\hline Assisted living facility & 3.5 & 6.1 & 7.5 & 11.9 & 13.3 & 6.7 \\
\hline \multicolumn{7}{|l|}{ Site, $\%$} \\
\hline Columbia & 44.9 & 34.1 & 44.1 & 42.4 & 50.0 & 42.6 \\
\hline Johns Hopkins & 23.2 & 24.2 & 19.4 & 20.3 & 36.7 & 23.5 \\
\hline Massachusetts General & 31.8 & 41.7 & 36.6 & 37.3 & 13.3 & 34.0 \\
\hline \multicolumn{7}{|l|}{ Clinical characteristics } \\
\hline MMSE, mean (SD) & $\begin{array}{l}22.0 \\
(3.7)\end{array}$ & $\begin{array}{l}19.6 \\
(6.0)\end{array}$ & $\begin{array}{l}19.1 \\
(6.2)\end{array}$ & $\begin{array}{l}17.7 \\
(7.4)\end{array}$ & $\begin{array}{l}15.7 \\
(7.8)\end{array}$ & $\begin{array}{r}20.1 \\
(5.7)\end{array}$ \\
\hline BDRS total, mean (SD) & $\begin{array}{c}3.6 \\
(2.2)\end{array}$ & $\begin{array}{c}5.2 \\
(3.2)\end{array}$ & $\begin{array}{c}5.6 \\
(3.4)\end{array}$ & $\begin{array}{c}6.8 \\
(3.9)\end{array}$ & $\begin{array}{c}8.1 \\
(3.5)\end{array}$ & $\begin{array}{c}5.0 \\
(3.3)\end{array}$ \\
\hline Behavioral problems, $\%$ & 42.4 & 49.2 & 60.2 & 57.6 & 60.0 & 50.6 \\
\hline EPS, \% & 14.1 & 20.5 & 18.3 & 23.7 & 16.7 & 17.7 \\
\hline Depressive symptoms, $\%$ & 20.2 & 24.2 & 17.2 & 11.9 & 23.3 & 19.7 \\
\hline Psychotic symptoms, \% & 31.3 & 32.6 & 36.6 & 40.7 & 40.0 & 34.5 \\
\hline Modified comorbidity index & $\begin{array}{c}0.8 \\
(0.9)\end{array}$ & $\begin{array}{c}0.8 \\
(1.0)\end{array}$ & $\begin{array}{c}0.8 \\
(1.0)\end{array}$ & $\begin{array}{c}0.8 \\
(0.9)\end{array}$ & $\begin{array}{c}0.8 \\
(0.9)\end{array}$ & $\begin{array}{c}0.8 \\
(0.9)\end{array}$ \\
\hline
\end{tabular}
clinical characteristics

* At baseline, data were collected from 198 patients. At year 1 and each year thereafter through year 4 , data were collected from $132,93,59$, and 30 patients from the original 198 patients for a total number of 524 observations.

MMSE $=$ Mini-Mental State Examination (range 0 to 30 ); BDRS = Blessed Dementia Rating Scale (range 0 to 17); EPS = extrapyramidal signs.

mented, and $9.7 \%$ were severely demented. Neurologists' estimate of duration of illness at baseline was 4.1 years $(\mathrm{SD}=2.2$ years $)$. At baseline, half of the patients did not have any comorbid conditions, $32 \%$ had one, $10 \%$ had two, $6 \%$ had three, and $2 \%$ had four comorbid conditions. On average, patients had less than one comorbid condition (mean $=0.8)$. The most common comorbid conditions at baseline included hypertension $(36.1 \%)$, diabetes $(9.7 \%)$, and myocardial infarction $(6.7 \%)$.

Utilization and annual per-patient costs over time. Table 2 presents data on utilization rates, intensity of use, and annual direct costs for medical and nonmedical care over time. All patients used some type of medical care each year, mainly because of high rates of medication use (>96\% each year). There were no discernible trends over 
Table 2 Descriptive statistics of utilization and costs over time

\begin{tabular}{|c|c|c|c|c|c|c|}
\hline & Baseline & Year 1 & Year 2 & Year 3 & Year 4 & All sample \\
\hline Sample size & 198 & 132 & 93 & 59 & 30 & 524 \\
\hline \multicolumn{7}{|l|}{ Utilization rate, $\%$} \\
\hline \multicolumn{7}{|l|}{ Medical care } \\
\hline Medication & 96.5 & 98.5 & 100.0 & 98.3 & 100.0 & 98.1 \\
\hline Outpatient treatment & 72.7 & 66.7 & 75.3 & 71.2 & 70.0 & 71.4 \\
\hline Assistive device & 42.9 & 31.8 & 37.6 & 40.7 & 50.0 & 38.9 \\
\hline Hospitalization & 21.2 & 20.5 & 15.1 & 25.4 & 20.0 & 20.4 \\
\hline Nonmedical care & 15.7 & 28.0 & 24.7 & 27.1 & 40.0 & 23.7 \\
\hline \multicolumn{7}{|l|}{ Intensity of use, mean (SD) } \\
\hline \multirow[t]{2}{*}{ Medication } & 6.4 & 7.5 & 7.4 & 7.7 & 8.1 & 7.1 \\
\hline & $(3.5)$ & (3.6) & (3.1) & $(3.7)$ & (3.8) & (3.5) \\
\hline \multirow[t]{2}{*}{ Outpatient treatment } & 2.0 & 1.9 & 1.9 & 2.0 & 1.9 & 2.0 \\
\hline & $(2.1)$ & (2.1) & $(2.2)$ & (2.3) & (2.4) & (2.1) \\
\hline \multirow[t]{2}{*}{ Assistive device } & 0.8 & 0.6 & 0.6 & 0.8 & 1.3 & 0.7 \\
\hline & (1.3) & (1.2) & (1.2) & (1.3) & (2.3) & (1.3) \\
\hline \multirow[t]{2}{*}{ Hospitalization } & 0.3 & 0.2 & 0.2 & 0.4 & 0.4 & 0.3 \\
\hline & $(0.6)$ & $(0.5)$ & $(0.5)$ & $(0.7)$ & $(0.9)$ & $(0.6)$ \\
\hline \multicolumn{7}{|l|}{ Per-patient cost, mean (SD) } \\
\hline \multirow[t]{2}{*}{ Medication } & 2,872 & 3,349 & 3,874 & 4,186 & 4,301 & 3,403 \\
\hline & $(1,857)$ & $(2,014)$ & $(2,866)$ & $(2,604)$ & $(2,639)$ & $(2,294)$ \\
\hline \multirow[t]{2}{*}{ Outpatient treatment } & 1,786 & 1,397 & 1,458 & 1,374 & 1,589 & 1,559 \\
\hline & $(3,318)$ & $(3,351)$ & $(2,703)$ & $(2,183)$ & $(2,796)$ & $(3,046)$ \\
\hline \multirow[t]{2}{*}{ Assistive device } & 144 & 175 & 189 & 184 & 300 & 172 \\
\hline & (337) & $(493)$ & $(648)$ & $(437)$ & $(448)$ & $(460)$ \\
\hline \multirow[t]{2}{*}{ Hospitalization } & 3,089 & 2,209 & 3,182 & 7,155 & 4,387 & 3,627 \\
\hline & $(8,081)$ & $(6,049)$ & $(11,639)$ & $(20,482)$ & $(16,407)$ & $(12,053)$ \\
\hline \multirow[t]{2}{*}{ Total medical care } & 7,105 & 7,890 & 8,699 & 12,899 & 10,577 & 8,753 \\
\hline & $(7,686)$ & $(9,060)$ & $(12,838)$ & $(20,301)$ & $(17,311)$ & $(12,875)$ \\
\hline \multirow[t]{2}{*}{ Total nonmedical care } & 1,349 & 5,000 & 4,672 & 2,429 & 9,348 & 3,835 \\
\hline & $(7,527)$ & $(16,339)$ & $(18,365)$ & $(5,709)$ & $(17,057)$ & $(14,121)$ \\
\hline \multirow[t]{2}{*}{ Total direct cost } & 9,239 & 12,105 & 13,371 & 15,328 & 19,925 & 12,587 \\
\hline & $(12,125)$ & $(19,514)$ & $(23,055)$ & $(20,968)$ & $(29,104)$ & $(20,849)$ \\
\hline
\end{tabular}

time in the utilization rates of medications, outpatient treatments or procedures, assistive devices, and hospitalizations. Utilization rate of nonmedical care increased substantially from $15.7 \%$ at baseline to $40 \%$ at year 4 . Average number of medications taken increased from 6.4 at baseline to 8.1 in year 4 (a $26.5 \%$ increase). Average intensity of use did not change substantially for outpatient treatments or procedures, assistive devices, and hospitalizations.

In terms of average per-patient cost, cost of outpatient treatments or procedures, assistive devices, and hospitalizations fluctuated year to year, but medication cost increased steadily from $\$ 2,872$ to $\$ 4,301$ (a 50\% increase). Total medical care costs and nonmedical care costs both increased substantially, from $\$ 7,105$ to $\$ 10,577$ (a $49 \%$ increase) and from $\$ 1,349$ to $\$ 9,348$ (a 7-fold increase). Taken together, in this group of patients, total direct cost per patient doubled from $\$ 9,239$ at baseline to $\$ 19,925$ at year 4.

Adjusted medical costs over time. Table 3 presents results of random effects regression models of log cost on patients' clinical and sociodemographic characteristics. We began by specifying a simple model with only a random intercept (results not shown). Results of the random intercept model suggested that total direct cost increased by $16 \%$ each year, but cost differed substantially across pa- tients. A second model that included both a random intercept and a random slope suggested that total direct cost increased by $13 \%$ each year, and there were substantial differences in both baseline cost and rate of increase in cost between patients. Our final model included both random intercept and random slope terms and estimated the effects on direct cost of patients' clinical and sociodemographic characteristics. Results of this model (table 3) suggested that patients' clinical and sociodemographic variables explained much of the time effect that was observed. Specifically, higher BDRS scores and higher number of comorbid conditions were associated with higher direct costs; women and patients living at home were associated with lower direct costs. The coefficient estimate on year in table 3 became insignificant, and that of total direct cost increased only by $1.2 \%$ each year after controlling for subjects' clinical and sociodemographic variables.

Table 3 also presents marginal effects of each variable on direct cost. For continuous explanatory variables, we defined the marginal effect of an explanatory variable as the proportional change in cost for a unit change in the explanatory variable, holding all other variables constant. For dichotomous explanatory variables, we defined the marginal effect of an explanatory variable as the proportional change in cost as the explanatory variable changes from the reference group, holding all other variables con- 
Table 3 Random effects models of total direct costs

\begin{tabular}{|c|c|c|c|}
\hline \multirow[b]{2}{*}{ Fixed effects parameters } & \multicolumn{3}{|c|}{ Dependent variable, log (cost) } \\
\hline & Coef & SE & $\begin{array}{c}\text { Marginal } \\
\text { effect }\end{array}$ \\
\hline Year & 0.012 & 0.038 & 1.171 \\
\hline MMSE score & -0.001 & 0.009 & -0.082 \\
\hline BDRS score & 0.077 & 0.020 & $7.705 \ddagger$ \\
\hline Number of comorbidities & 0.143 & 0.051 & $14.301 \ddagger$ \\
\hline $\begin{array}{l}\text { Behavior problems }(1=\text { present, } \\
\qquad 0=\text { absent })\end{array}$ & 0.056 & 0.090 & 5.347 \\
\hline $\begin{array}{l}\text { Extrapyramidal signs }(1=\text { present, } \\
\quad 0=\text { absent })\end{array}$ & 0.010 & 0.115 & 0.386 \\
\hline $\begin{array}{l}\text { Depressive symptoms }(1=\text { present } \\
\quad 0=\text { absent })\end{array}$ & 0.126 & 0.101 & 12.874 \\
\hline $\begin{array}{l}\text { Psychotic symptoms }(1=\text { present } \\
\quad 0=\text { absent })\end{array}$ & 0.102 & 0.096 & 10.198 \\
\hline $\begin{array}{l}\text { Younger than } 65 \mathrm{y} \\
\qquad(1=\text { yes, } 0=\text { no })\end{array}$ & -0.115 & 0.168 & -12.080 \\
\hline Women $(1=$ yes, $0=$ no $)$ & -0.238 & 0.100 & $-21.545 \dagger$ \\
\hline Lives at home $(1=$ yes, $0=$ no $)$ & -0.225 & 0.130 & $-20.846^{*}$ \\
\hline \multicolumn{4}{|l|}{$\begin{array}{l}\text { Site }(\text { reference }=\text { Massachusetts } \\
\quad \text { General) }\end{array}$} \\
\hline Columbia & 0.303 & 0.118 & $34.435 \dagger$ \\
\hline Johns Hopkins & 0.227 & 0.138 & $24.233^{*}$ \\
\hline
\end{tabular}

$* p<0.10$.

$\dagger p<0.05$.

$\ddagger p<0.01$.

Coef $=$ coefficient MMSE $=$ Mini-Mental State Examination; BDRS $=$ Blessed Dementia Rating Scale.

stant. Results showed that after controlling for other variables, a one-point increase in the BDRS score increased total direct cost by $7.7 \%$, and one more comorbid condition increased total direct cost by $14.3 \%$. Log cost was 0.238 lower for women than for men, corresponding to a $21.5 \%$ lowered total direct cost for women as compared with men. Log cost was 0.225 lower for patients living at home than those living in an institutional setting, corresponding to a $20.8 \%$ lowered direct cost for patients living at home. Other clinical variables (MMSE scores, presence of behavioral problems, EPS, depressive symptoms, and psychotic symptoms) were not significantly associated with total direct cost. Finally, results also showed substantial site differences in costs, with the Boston site having lower cost than Baltimore and New York City sites.

Discussion. In this study, we estimated empirically long-term trajectories of direct health care cost for a sample of patients initially at early stages of $\mathrm{AD}$ and related them to patients' clinical and sociodemographic characteristics. As discussed below, we will investigate indirect costs in a separate report. We estimated that total direct cost of caring for patients with $\mathrm{AD}$ was $\$ 9,239$ per patient per year at baseline, when all patients were in the early stages of the disease. We also estimated that total direct cost increased substantially at each subsequent follow-up. By year 4, total direct cost more than doubled to $\$ 19,925$ per patient per year. The magnitude of these cost estimates are consistent with existing studies. ${ }^{21,46}$

With longitudinal data, we showed that much of the cost increases were explained by patients' clinical and demographic variables. Without controlling for other covariates, total direct cost increased by approximately $13 \%$ each year. After controlling for patients' clinical and sociodemographic variables, however, the time (year) effect became insignificant and was only associated with a $1.2 \%$ increase in direct cost each year.

The longitudinal analysis in this study confirms results from an earlier cross-sectional study using the same sample. ${ }^{21}$ There we found that small differences in function were associated with large differences in medical care costs; this study further showed that the relationship between disease cost and function was consistent over time. As a secondary analysis, we tested our models using BDRS factors instead of the total score to examine which specific domains were most sensitive to cost increases. As a group, the BDRS factors were significantly associated with higher costs. Both IADLs and BADLs factors were associated with higher direct costs. Our longitudinal analysis also confirms the relationship between comorbidities and higher costs. A limitation of using the number of comorbidities is that it treats each condition equally when some conditions may be more costly than others. We tested which comorbid conditions were associated with higher cost by including each condition in our estimation model instead of using the modified comorbidity index. Results show that myocardial infarction, chronic obstructive pulmonary disease, and chronic liver disease were significantly associated with higher direct cost. These results are consistent with the findings in the Odense study; this study reported that between baseline and 3-year follow-up interviews in a sample of patients initially living in the community, patients' total health care costs were significantly associated with disease progression (measured by transition to moderate or severe dementia), development of and declines in functional abilities, and transition in living arrangement (moving from community to residential homes). ${ }^{20}$

The effects of psychotic and behavior problems and extrapyramidal signs on the cost of caring for patients with $\mathrm{AD}$ are not yet well understood. Similar to our baseline study, but contrary to several cross-sectional studies that examined the effects of behavior problems ${ }^{12,15,16}$ and $\mathrm{EPS}^{18}$ on $\mathrm{AD}$ costs, we did not find the presence of psychotic symptoms, behavior problems, or EPS to be significantly associated with increased direct cost of care. We believe the nonsignificant results may be due to the roughness of the measures used in this study. For example, subcategories of extrapyramidal and psychotic symptoms were grouped together, and we only used dichotomous gradations of severity. Additionally, behavioral and psychiatric symptoms in $\mathrm{AD}$ fluctuate 
over time, and particular symptoms can occur any time during the course of $\mathrm{AD} .{ }^{34}$ Persistence of these symptoms also differs from symptom to symptom. ${ }^{47}$ Although our multivariate model with timedependent covariates takes into account the status of patients' symptoms (presence or absence) at each visit, we will examine in detail the effects on costs of finer gradations of subtype and severity of each symptom in future studies.

Consistent with other studies, ${ }^{3,7}$ we found that costs are substantially lower for patients living at home than for those living in an institutional setting. Possibly because the proportion of patients who lived in retirement homes and assisted living facilities were small, we were unable to separate out the effects on cost of different institutional living arrangements. The lower direct cost at home as compared with that in institutional settings suggests that interventions aimed at delaying or preventing institutionalization could reduce direct cost of care. However, potential cost savings in direct cost of care with delayed institutionalization need to be balanced with the potential increase in cost to caregivers providing unpaid care. In our future work, we will explore the relationship between the cost of caregiving and institutionalization.

In this study, we also found that women had $21 \%$ lowered total direct cost compared with men. This result is consistent with earlier studies that found differences in health care utilization between men and women. For example, one study found that in a sample of patients who eventually developed $\mathrm{AD}$, use of Medicare reimbursed primary care was lower in women than in men. ${ }^{48} \mathrm{An}$ other study of a nationally representative sample of noninstitutionalized disabled elderly reported lower use of both paid home care and informal care in women than in men, even within married households. ${ }^{49}$ Although the results of this study and these earlier studies are consistent and suggest gender disparities in health care utilization, this result requires further investigation.

We found substantial cost differences across sites. This result is consistent with regional differences in health services utilization and costs documented in the literature ${ }^{50}$ and, more specifically, a recent study on service utilization and costs among patients with AD. ${ }^{51}$ Because different sites were included in these studies, results are not directly comparable across studies. Further investigations are needed to examine whether variations in utilization and costs reflect differences in regional preferences, availability or access of services, ethnic and cultural differences, or socioeconomic factors.

At this point in the study, 16 of the 198 patients in the analysis sample have died, contributing to 42 observations in the longitudinal sample. Many studies show substantially higher medical care utilization and cost during the last year of life. ${ }^{52,53}$ To examine the effects of including patients who died in our analysis, we performed secondary analyses in the following two ways. First, we reestimated our model excluding the last observation of the patients who died (i.e., 16 observations dropped). We also reestimated our model excluding these patients entirely (i.e., 42 observations dropped). Results of these models were similar to those reported in this study.

There are several limitations to our study. Patients were selected from tertiary care university hospitals and specialized diagnostic and treatment centers and thus represent a nonrandom sample of those affected by $\mathrm{AD}$ in the population. The patients in our sample also were predominantly white and highly educated. Caution is needed in generalizing the results of this study to patients of other ethnicities, to patients with lower levels of education and income, and to community $\mathrm{AD}$ patients. Future research will need to examine $\mathrm{AD}$ cost trajectories in samples that are more representative of the general population.

It should be noted that the cost estimates reported in this study are total direct cost associated with caring for patients with $\mathrm{AD}$ and not incremental costs due to $\mathrm{AD}$. For example, costs of medications include costs from all medications and not only those from antidementia agents. To estimate the incremental costs due to $\mathrm{AD}$, a comparison longitudinal sample of non-AD patients with otherwise similar characteristics is needed. However, the construction of a non-AD comparison group is beyond the scope of this study. Many studies have documented the high indirect cost of care for patients with $\mathrm{AD}$ and documented its association with a number of clinical variables..$^{8,10,15,21,51,54,55}$ Most of these studies, like those that examined direct cost of care, are cross-sectional. In future studies, we will examine the trajectories of indirect cost of caring for patients with $\mathrm{AD}$ and examine its relationship with important clinical characteristics.

In this study, resource utilization was reported by informants (mostly caregivers) and patients. Self-reported data may be problematic in studies of patients with $\mathrm{AD}$ because of the patients' inability to reliably report on service utilization and the necessity of using proxies to obtain information. We are not aware of any studies on the accuracy of caregiver-reported resource utilization data. However, caregivers have been shown to accurately report information on care recipients' medical conditions. ${ }^{56}$ Our results may be biased if there are systematic differences between caregivers' reports on medical conditions and resource use. However there is no reason to believe this is the case.

In general, confidence in our findings is strengthened by several factors. A major contribution of the current analyses lies in the careful diagnosis and clinical follow-up that patients received. Clinical diagnosis took place in university hospitals with specific expertise in dementia and was based on uniform application of widely 
accepted criteria via consensus diagnostic conference procedures. The clinical diagnosis of $\mathrm{AD}$ has been confirmed in a high proportion (93\%) of those who have come to postmortem evaluation. ${ }^{24}$ The patients were followed up prospectively, which eliminates the potential biases inherent in deriving information from retrospective chart reviews. Evaluations were performed annually, which provides multiple assessments of cost and therefore permits more accurate coefficient estimates. Our cohort had a high rate of follow-up participation, with few missing data. Clinical signs of interest were ascertained and coded in a standardized fashion at each visit. Finally, patients were recruited at early stages of the disease and followed for long periods of time. Analysis is not compressed in time, and the cohort describes the full range of progression over time. Longer-term effects on costs are therefore more easily interpreted.

\section{References}

1. Meek P, McKeithan K, Schumock G. Economic considerations in Alzheimer's disease. Pharmacotherapy 1998;18:68-73.

2. Centers for Disease Control and Prevention, National Center for Chronic Disease Prevention and Health Promotion. Unrealized prevention opportunities: Reducing the health and economic burden of chronic illness, November 2000.

3. Rice DP, Fox PJ, Max W, et al. The economic burden of Alzheimer's disease care. Health Aff (Millwood) 1993;12:164-176.

4. Max W, Webber P, Fox P. Alzheimer's disease: the unpaid burden of caring. J Aging Health 1995;7:179-199.

5. Ernst RL, Hay JW, Fenn C, Tinklenberg J, Yesavage JA. Cognitive function and the costs of Alzheimer disease: an exploratory study. Arch Neurol 1997;54:687-693.

6. Hux MJ, O’Brien BJ, Iskedjian M, Goeree R, Gagnon M, Gauthier S. Relation between severity of Alzheimer's disease and costs of caring. CMAJ 1998;159:457-465.

7. Leon J, Cheng CK, Neumann PJ. Alzheimer's disease care: costs and potential savings. Health Aff (Millwood) 1998;17:206-216

8. Souetre E, Thwaites RM, Yeardley HL. Economic impact of Alzheimer's disease in the United Kingdom: cost of care and disease severity for non-institutionalised patients with Alzheimer's disease. Br J Psychiatry 1999;174:51-55.

9. Taylor DH Jr, Sloan FA. How much do persons with Alzheimer's disease cost Medicare? J Am Geriatr Soc 2000;48:639-646.

10. Moore MJ, Zhu CW, Clipp EC. Informal costs of dementia care: estimates from the National Longitudinal Caregiver Study. J Gerontol B Psychol Sci Soc Sci 2001;56:S219-S228.

11. Small GW, McDonnell DD, Brooks RL, Papadopoulos G. The impact of symptom severity on the cost of Alzheimer's disease. J Am Geriatr Soc 2002;50:321-327.

12. Zhu C, Moore M, Clipp E. Dementia problem behavior and the production of informal caregiving services. J Econ Household 2003;1:59-76.

13. Gutterman EM, Markowitz JS, Lewis B, Fillit H. Cost of Alzheimer's disease and related dementia in managed-Medicare. J Am Geriatrics Soc 1999;47:1065-1071.

14. Fillit HM. The pharmacoeconomics of Alzheimer's disease. Am J Manag Care 2000;6:S1139-S1144.

15. Beeri MS, Werner P, Davidson M, Noy S. The cost of behavioral and psychological symptoms of dementia (BPSD) in community dwelling Alzheimer's disease patients. Int J Geriatr Psychiatry 2002;17:403408

16. Murman DL, Chen Q, Powell MC, Kuo SB, Bradley CJ, Colenda CC. The incremental direct costs associated with behavioral symptoms in AD. Neurology 2002;59:1721-1729.

17. Murman DL, Colenda CC. The economic impact of neuropsychiatric symptoms in Alzheimer's disease: can drugs ease the burden? Pharmacoeconomics 2005;23:227-242.

18. Murman DL, Kuo SB, Powell MC, Colenda CC. The impact of parkinsonism on costs of care in patients with $\mathrm{AD}$ and dementia with Lewy bodies. Neurology 2003;61:944-949.

19. Wolstenholme J, Fenn P, Gray A, Keene J, Jacoby R, Hope T. Estimating the relationship between disease progression and cost of care in dementia. Br J Psychiatry 2002;181:36-42.

20. Andersen CK, Lauridsen J, Andersen K, Kragh-Sorensen P. Cost of dementia: impact of disease progression estimated in longitudinal data. Scand J Public Health 2003;31:119-125.
21. Zhu C, Scarmeas N, Torgan R, et al. Clinical features associated with costs in early $\mathrm{AD}$ : baseline data from the predictors study. Neurology 2006;66:1021-1028.

22. Stern Y, Folstein M, Albert M, et al. Multicenter study of predictors of disease course in Alzheimer disease (the "predictors study"): I. Study design, cohort description, and intersite comparisons. Alzheimer Dis Assoc Disord 1993;7:3-21.

23. Richards M, Folstein M, Albert M, et al. Multicenter study of predictors of disease course in Alzheimer disease (the "predictors study"): II. Neurological, psychiatric, and demographic influences on baseline measures of disease severity Alzheimer Dis Assoc Disord 1993;7:2232.

24. Scarmeas N, Hadjigeorgiou GM, Papadimitriou A, et al. Motor signs during the course of Alzheimer disease. Neurology 2004;63:975-982.

25. Folstein MF, Folstein SE, McHugh PR. "Mini-Mental State": a practical method for grading the cognitive state of patients for the clinician. J Psychiatr Res 1975;12:189-198.

26. Stern Y, Sano M, Paulson J, Mayeux R. Modified Mini-Mental State Examination: validity and reliability. Neurology 1987;37:179.

27. Agency for Healthcare Research and Quality. HCUPnet, Healthcare Cost and Utilization Project [online]. Available at: http://www.ahrq.gov/ HCUPnet/. Accessed March 1, 2005.

28. Centers for Medicare and Medicaid Services. Clinical Diagnostic Laboratory Fee Schedule [online]. Available at: http://www.cms.hhs.gov/ providers/pufdownload/. Accessed March 1, 2005.

29. Centers for Medicare and Medicaid Services. Healthcare Common Procedure Coding System (HCPCS) [online]. Available at: http://www.cms. hhs.gov/providers/pufdownload/anhcpcdl.asp. Accessed March 1, 2005.

30. Drug topics red book. Montvale, NJ: Medical Economics Company/ Thompson Medical Economics, 2000.

31. Blessed G, Tomlinson BE, Roth M. The association between quantitative measures of dementia and of senile change in the cerebral grey matter of elderly subjects. Br J Psychiatry 1968;114:797-811.

32. Devanand DP, Miller L, Richards M, et al. The Columbia University Scale for Psychopathology in Alzheimer's Disease. Arch Neurol 1992;49: 371-376.

33. Scarmeas N, Brandt J, Albert M, et al. Association between the APOE genotype and psychopathologic symptoms in Alzheimer's disease. Neurology 2002;58:1182-1188.

34. Scarmeas N, Brandt J, Albert M, et al. Delusions and hallucinations are associated with worse outcome in Alzheimer disease. Arch Neurol 2005;62:1601-1608.

35. Stern MB, Hurting HI. The clinical characteristics of Parkinson's disease and parkinsonian syndromes: diagnosis and assessment. In: The comprehensive management of Parkinson's disease. New York: PMA Corp, 1978:3-50.

36. Richards M, Marder K, Bell K, Dooneief G, Mayeux R, Stern Y. Interrater reliability of extrapyramidal signs in a group assessed for dementia. Arch Neurol 1991;48:1147-1149.

37. Scarmeas N, Albert M, Brandt J, et al. Motor signs predict poor outcomes in Alzheimer disease. Neurology 2005;64:1696-1703.

38. Charlson ME, Pompei P, Ales KL, MacKenzie CR. A new method of classifying prognostic comorbidity in longitudinal studies: development and validation. J Chronic Dis 1987;40:373-383.

39. Menzin J, Lang K, Friedman M, Neumann P, Cummings JL. The economic cost of Alzheimer's disease and related dementias to the California Medicaid program ("Medi-Cal") in 1995. Am J Geriatr Psychiatry 1999;7:300-308.

40. Council of Economic Advisers. Economic report of the President. Washington, DC, 2003

41. Baltagi B. Analysis of panel data. New York: Wiley and Sons, 1995

42. Singer J, Willet J. Applied longitudinal data analysis: Modeling change and event occurrence. New York: Oxford University Press, 2003.

43. Kennedy P. Estimation with correctly interpreted dummy variables in semilogarithmic equations. Am Economic Rev 1981;71:801.

44. Stata [software program]. Version 9. College Station, TX.

45. Hughes CP, Berg L, Danziger WL, Coben LA, Martin RL. A new clinical scale for the staging of dementia. Br J Psychiatry 1982;140: 566-572.

46. Bloom BS, de Pouvourville N, Straus WL. Cost of illness of Alzheimer's disease: how useful are current estimates? Gerontologist 2003;43:158164.

47. Devanand DP, Jacobs DM, Tang MX, et al. The course of psychopathologic features in mild to moderate Alzheimer disease. Arch Gen Psychiatry 1997;54:257-263.

48. Albert SM, Glied S, Andrews H, Stern Y, Mayeux R. Primary care expenditures before the onset of Alzheimer's disease. Neurology 2002; 59:573-578.

49. Katz SJ, Kabeto M, Langa KM. Gender disparities in the receipt of home care for elderly people with disability in the United States. JAMA 2000;284:3022-3027.

50. Fisher ES, Wennberg DE, Stukel TA, Gottlieb DJ, Lucas FL, Pinder EL. The implications of regional variations in Medicare spending. Part 1: the content, quality, and accessibility of care. Ann Intern Med 2003 138:273-287.

51. Harrow BS, Mahoney DF, Mendelsohn AB, et al. Variation in cost of informal caregiving and formal-service use for people with 
Alzheimer's disease. Am J Alzheimers Dis Other Demen 2004;19: 299-308.

52. Hogan C, Lunney J, Gabel J, Lynn J. Medicare beneficiaries' costs of care in the last year of life. Health Aff (Millwood) 2001;20:188-195.

53. Hoover DR, Crystal S, Kumar R, Sambamoorthi U, Cantor JC. Medical expenditures during the last year of life: findings from the 1992-1996 Medicare current beneficiary survey. Health Serv Res 2002;37:16251642.
54. Bianchetti A, Frisoni G, Ghisla K, Trabucchi M. Clinical predictors of the indirect costs of Alzheimer's disease. Arch Neurol 1998;55:130-131.

55. Leon J, Neumann PJ. The cost of Alzheimer's disease in managed care: a cross-sectional study. Am J Manag Care 1999;5:867-877.

56. Corder LS, Woodbury MA, Manton KG. Proxy response patterns among the aged: effects on estimates of health status and medical care utilization from the 1982-1984 long-term care surveys. J Clin Epidemiol 1996; 49:173-182.

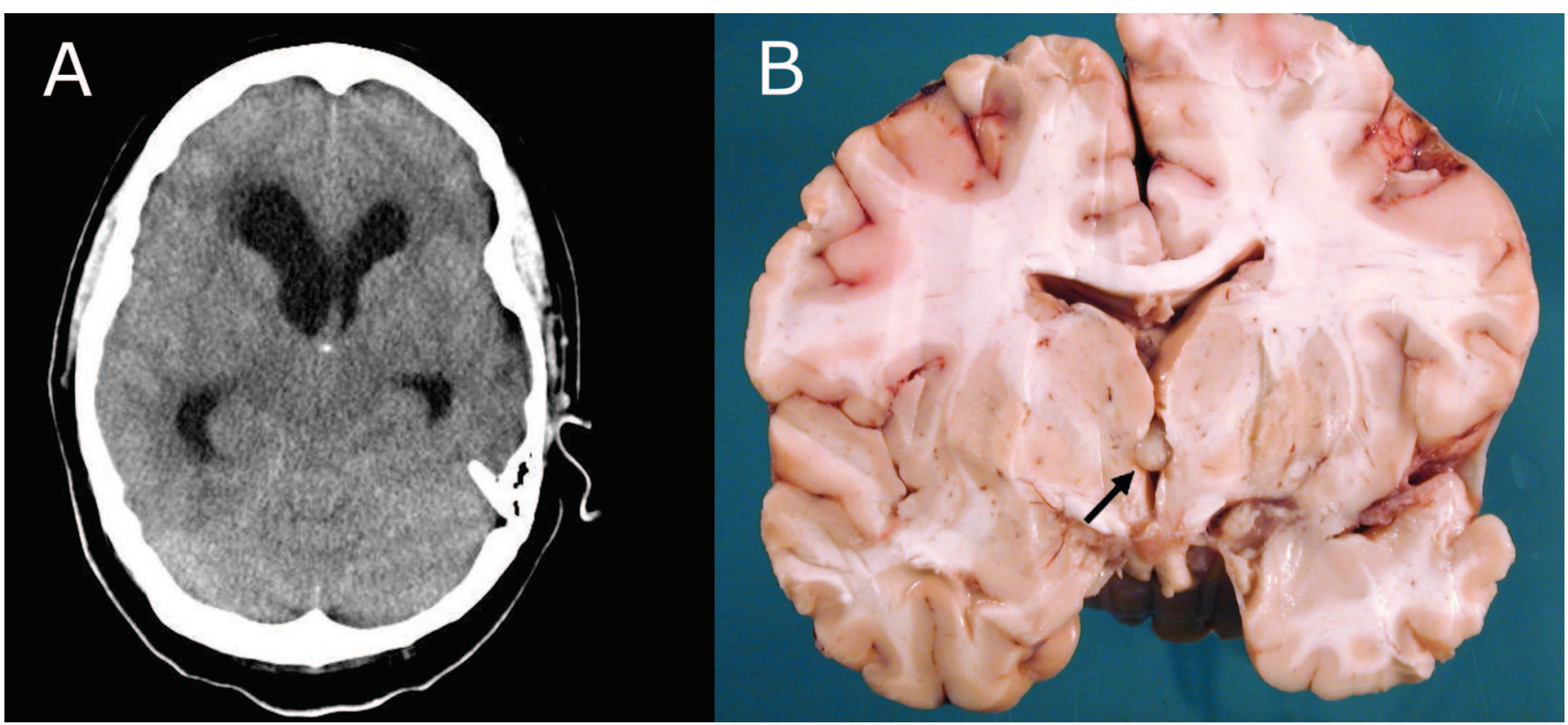

Figure. On admission, a CT scan showed a biventricular hydrocephalus (A). Autopsy showed a colloid cyst of the third ventricle (arrow) (B).

\section{Sudden death after air travel in a patient with colloid cyst}

B.C. ter Meulen, MD, Department of Neurology; J.M. Kros, MD, PhD, Department of Pathology; and B.C. Jacobs, MD, PhD, Departments of Neurology and Immunology, Erasmus Medical Centre, Rotterdam, The Netherlands

A 19-year-old previously healthy woman presented with sudden headache and nausea after a transcontinental flight. She

\section{Disclosure: the authors report no conflicts of interest.}

Address correspondence and reprint requests to Dr. B.C. Jacobs, Department of Neurology, Erasmus Medical Centre, Dr. Molewaterplein 40, 3015 GD Rotterdam, The Netherlands; e-mail: b.jacobs@erasmusmc.nl rapidly became comatose. A CT scan showed a biventricular hydrocephalus (figure). A ventricular drain was inserted to relieve intracranial pressure, but her clinical condition failed to improve. The patient died 24 hours after admission. The most notable finding at autopsy was a colloid cyst obstructing the foramen of Monro. Few similar cases have been reported..$^{1,2} \mathrm{We}$ conclude that patients harboring colloid cysts are prone to barotrauma with fatal outcome.

Copyright @ 2006 by AAN Enterprises, Inc.

1. Nelson E, Haymaker W. Colloid cysts of the third ventricle in flyers. Report of three fatal cases. J Aviation Med 1957;28:352-363.

2. Buttner A, Winkler PA, Eisenmenger W, et al. Colloid cysts of the third ventricle with fatal outcome: a report of two cases and review of the literature. Int J Legal Med 1997;110:260-266. 


\title{
Longitudinal study of effects of patient characteristics on direct costs in Alzheimer disease
}

C. W. Zhu, N. Scarmeas, R. Torgan, et al.

Neurology 2006;67;998; Prepublished online August 16, 2006;

DOI 10.1212/01.wnl.0000230160.13272.1b

This information is current as of December 3, 2010

\author{
Updated Information \& \\ Services \\ including high resolution figures, can be found at: \\ http://www.neurology.org/content/67/6/998.full.html \\ References \\ This article cites 46 articles, 28 of which can be accessed free \\ at: \\ http://www.neurology.org/content/67/6/998.full.html\#ref-list-1 \\ Citations \\ This article has been cited by 14 HighWire-hosted articles: \\ http://www.neurology.org/content/67/6/998.full.html\#related-ur \\ ls \\ Subspecialty Collections \\ This article, along with others on similar topics, appears in the \\ following collection(s): \\ All Health Services Research \\ http://www.neurology.org/cgi/collection/all_health_services_res \\ earch \\ Cost effectiveness/economic \\ http://www.neurology.org/cgi/collection/cost_effectiveness_eco \\ nomic \\ Alzheimer's disease \\ http://www.neurology.org/cgi/collection/alzheimers_disease \\ Permissions \& Licensing \\ Information about reproducing this article in parts (figures, \\ tables) or in its entirety can be found online at: \\ http://www.neurology.org/misc/Permissions.shtml \\ Reprints \\ Information about ordering reprints can be found online: \\ http://www.neurology.org/misc/reprints.shtml
}

